\title{
ENCAPSULATION OF RED GINGER OLEORESIN (ZINGIBER OFFICINALE VAR RUBRUM) WITH CHITOSAN AS WALL MATERIAL
}

\author{
JAYANUDIN ${ }^{1}$, ROCHMADI $^{2}$ \\ ${ }^{1}$ Chemical Engineering Department, University of Sultan Ageng Tirtayasa. ${ }^{2}$ Chemical Engineering Department, Gadjah Mada University \\ Email: jayanudin@untirta.ac.id
}

Received: 20 Oct 2016 Revised and Accepted: 19 Jun 2017

\begin{abstract}
Objective: This research aims to determine the effect of the spray drying condition against encapsulation efficiency and characterization microcapsules of red ginger oleoresin.

Methods: Preparation of encapsulation begun with the formation of emulsions by mixing red ginger oleoresin with chitosan solution which was dissolved with acetic acid $2 \%(\mathrm{v} / \mathrm{v})$. The weight ratio of chitosan with red ginger oleoresin was $1: 1,2: 1$ and $3: 1$ and then stirred using a homogenizer while added $2 \mathrm{ml}$ tween 80 for $10 \mathrm{~min}$. The size of emulsion droplet was measured using nanoparticle analyzer (NPA). The emulsion is formed and then inserted into the feed tank of a spray dryer. Inlet temperature of the spray dryer used in the $180{ }^{\circ} \mathrm{C}, 190{ }^{\circ} \mathrm{C}$ and $200{ }^{\circ} \mathrm{C}$; and the spray dryer outlet temperature was $85{ }^{\circ} \mathrm{C}$, feed rate at $2 \mathrm{~L} / \mathrm{h}$. The microcapsules formed were then analyzed encapsulation efficiency and characterization using scanning electron microscopy (SEM) and fourier transform infrared spectroscopy (FTIR).

Results: Based on the research that has been done, the smallest effective diameter of the emulsion droplets was $216.4 \pm 1.5 \mathrm{~nm}$ and the largest was $2109.2 \pm 46.1 \mathrm{~nm}$. The value of encapsulation efficiency ranged between $83.33 \pm 0.42 \%-99.15 \pm 0.02 \%$. Increasing the weight ratio of chitosan with red ginger oleoresin and increase the spray drying inlet temperature, the encapsulation efficiency is also increased. The highest encapsulation efficiency was $99.15 \pm 0.02 \%$ occurred at $200{ }^{\circ} \mathrm{C}$ of spray drying inlet temperature and the weight ratio of chitosan with red ginger oleoresin of $3: 1$. Morphology analysis of the surface of microcapsules using scanning electron microscope (SEM) showed that the inlet temperature of $200{ }^{\circ} \mathrm{C}$ was obtained microcapsules with smooth surfaces. The Fourier transforms infrared spectroscopy (FTIR) analysis results indicating the absence of new compounds is formed.
\end{abstract}

Conclusion: This research indicates that the spray drying conditions affecting the encapsulation efficiency and morphological characteristics of the red ginger oleoresin microcapsules.

Keywords: Chitosan, Encapsulation efficiency, Red ginger oleoresin, Spray drying, Surface oil, Total oil

(C) 2017 The Authors. Published by Innovare Academic Sciences Pvt Ltd. This is an open access article under the CC BY license (http://creativecommons.org/licenses/by/4.0/) DOI: http://dx.doi.org/10.22159/ijpps.2017v9i8.15632

\section{INTRODUCTION}

Red ginger (Zingiber officinale var. rubrum) was one of the families of Zingibereaceae. Red ginger can be used to flavourings in food and beverages also as a medicine. Ginger can be consumed as a paste, dried powder, candy (crystallized ginger) or as a flavoring of tea. Ginger also used as a seasoning for industries of food, beverage, and fragrance, in China for its pungent constituents and aromatic volatile constituents [1]. Red ginger (Zingiber officinale var. rubrum) is part of the ginger varieties that have a spicier flavour, the smaller size of the rhizome with red leather. Phenol and flavonoid compound red ginger is larger than the white ginger (Zingiber officinale roscoe) [2].

Ginger contains a volatile oil about $1 \%$ to $3 \%$ and also contains a non-volatile oil called oleoresin. The main components were identified from the ginger are sesquiterpene hydrocarbon and phenolic compounds which are gingerol and shogaol [3-5]. Ginger oleoresin is obtained from dried ginger by extraction using an organic solvent. Oleoresin is a viscous liquid, sticky and reddish brown [6]. The oleoresin contains the organoleptically volatile oil and pungent principles, together with fatty oil, resin, palmitic acid, carbohydrates and free fatty acids [7].

Bioactive components in ginger oleoresin can be used as an antioxidant [8-9], even antioxidant activity of ginger oleoresin was more effective than the others oleoresin and almost the same with the synthesis of antioxidants [10]. The component of 6-shogaol in red ginger oleoresin has effectively inhibited the growth of prostate cancer cells [11]. The compounds of 6-shogaol can be used to inhibit breast cancer cells and colon [12], and also effective in treating colon cancer [13].
Bioactive contained in ginger oleoresin such as gingerol, shogaol and zingerone that produce a hot sensation in the mouth. The gingerol, a series of chemical homologues differentiated by the length of their unbranched alkyl chains, were identified as the major active components in the fresh rhizome. Shogaol was formed from dehydration of gingerol during the heating process and storage [14].

The weakness of oleoresin are sensitive to light, heat and oxygen that can cause degradation of the bioactive component. Oleoresin degradation can be caused by changes in polymer involving fatty oil component of monoterpinic hydrocarbons (e. g., $\alpha$-pinene, $\beta$-pinene, limonene, sabinene) [15]. The shogaol also susceptible to acidic $\mathrm{pH}$ and heat treatment, they probably transform to non-pungent polymers. The pungency of oleoresins decreases steadily on storage as the gingerol are first transformed to the shogaol, which are in turn degraded [7, 16]. Encapsulation was a method that can be used to protect the active components oleoresin [17].

Encapsulation is a technique of coating the active ingredient of solids, liquids and gases using a thin layer as a wall material [18-19]. Encapsulation is used to protect the active ingredients such as polyphenols, enzyme, and antioxidant. Encapsulation is also used for controlled release [20]. The core can be composed of one or several materials and coating can be single or double layered [21]. This technique has been widely used for coating the organoleptic properties such as flavor and aroma [22]. Microcapsules or microspheres size are ideally less than $200 \mu \mathrm{m}$ [23].

The selection of wall material for encapsulation is one of the most important factors, as it relates to the encapsulation efficiency, protection and controlled release. Wall material serves to protect the core material from environmental influences such as light, heat, 
air oxidation, and the effects of acid and alkaline chemicals. Chitosan is one of the wall materials that can be used for the encapsulation process because chitosan are biocompatible, biodegradable and low toxic. Chitosan in recent years has been used for the development of oral drug delivery systems [24]. Chitosan can be used for the preparation of the mucoadhesive microspheres. Therefore, it is necessary to develop an oral drug delivery system that is comfortable for the patient [25].

Generally, methods of encapsulation are distinguished after the emulsion formation processes are chemical and physical methods. Spray drying is one of the physical method most widely used and the oldest method of encapsulation process which was discovered in 1930 [26]. The basic principle of spray drying is the process of spraying the material through the atomizer and then contacted with hot air to produce a fine powder. The resulting particle sizes of the spray drying are between 10-50 $\mu \mathrm{m}$ and a large size of 2-3 mm [20,27-28]. Although many techniques have been developed for microencapsulation, spray drying is the technology most commonly used in the food and pharmaceutical industries because it's low cost and the available equipment [22].

Effect of spray drying condition such as inlet temperature will have a significant impact, such as drying rate, product quality based on the encapsulation efficiency and morphology of microcapsules. This study aims to determine the effect of the spray drying condition and the weight ratio of wall material and ginger oleoresin as a core material to produce microcapsules with a higher encapsulation efficiency and analysis characterization of red ginger oleoresin microcapsules using scanning electron microscope (SEM) and Fourier transforms infrared spectroscopy (FTIR).

\section{MATERIALS AND METHODS}

\section{Materials}

Red ginger oleoresin was obtained from CV. M and $\mathrm{H}$ Farm, food grade chitosan was obtained from CV. Bio Chitosan Indonesia, nhexane form Merck, acetic acid 100\% from Merck and tween 80 from Sigma-Aldrich.

\section{Preparation of emulsion}

The process of emulsion formation refers to previously reported methods [29]. Chitosan solution with a concentration of $2 \%(\mathrm{~g} / \mathrm{v})$ was prepared by dissolving $20 \mathrm{~g}$ of chitosan with $2 \%(\mathrm{v} / \mathrm{v})$ acetic acid, than $1000 \mathrm{ml}$ chitosan solution mixed with red ginger oleoresin with a weight of $20 \mathrm{~g}, 10 \mathrm{~g}$ and $6.7 \mathrm{~g}$ to make the ratio of chitosan: oleoresin were $1: 1,2: 1$ and 3:1, and also added $2 \mathrm{ml}$ of tween 80 . The mixture was stirred using an Ika Werk Ultra Turrax homogenizer at 20,000 rpm for 10 min to form an emulsion. Droplet size of the emulsion was then analyzed using the Nano Particle Analyzer (NPA).

\section{Encapsulation of red ginger oleoresin}

The red ginger oleoresin encapsulation process using spray drying method was a modification of previous research [30-31]. The emulsion of red ginger oleoresin entered in the feed tank of a spray dryer and then flowed into the atomizer to contact with hot air. Inlet air temperature variations used in the spray dryer was $180^{\circ} \mathrm{C}, 190^{\circ} \mathrm{C}$ and $200^{\circ} \mathrm{C}$; outlet air temperature was maintained at $85^{\circ} \mathrm{C}$, feed rate at $2 \mathrm{~L} / \mathrm{h}$. Microcapsules powder that is formed then analyzed for encapsulation efficiency and characterization using scanning electron microscope (SEM and fourier transform infrared spectroscopy (FTIR).

\section{Emulsion droplet size analysis}

Emulsion droplet size analysis used the nanoparticle analyzer (NPA) Brookhaven 90 plus, with the following specifications: size range: 2 $\mathrm{nm}$ to $3 \mu \mathrm{m}$, diffusion coefficient range: $10-6$ to $10-9 \mathrm{~cm} 2 / \mathrm{sec}$, accuracy: \pm 1 to $2 \%$ with monodisperse samples, repeatability: \pm 1 to $2 \%$ with dust free samples, temperature control (optional): 5 to 75 ${ }^{\circ} \mathrm{C}$ on steps of $0.1{ }^{\circ} \mathrm{C}$, sample volume: $3 \mathrm{ml}$, results: mean and standard deviation calculated for size distribution by weight assuming a lognormal distribution.

\section{Scanning electron microscopy (SEM)}

Powder morphology of the red ginger oleoresin microcapsules was analysed using scanning electron microscopy (SEM) JEOL-type JSM-
$6510 \mathrm{LV}$ in coated with a thin layer of platinum, resolution: high vacuum mode: $3.0 \mathrm{~nm}(30 \mathrm{kV})$ and low vacuum mode: $4.0 \mathrm{~nm}(30$ $\mathrm{kV}$ ), accelerating voltage: 0.5 to $30 \mathrm{kV}$.

\section{Fourier transforms infrared spectroscopy (FTIR)}

Analysis of the interaction between the components in the microcapsules was performed using fourier transform infrared spectroscopy (FTIR) using $\mathrm{KBr}$ pellets, in a Shimadzu IR spectrophotometer, operating between 500 and $4000 \mathrm{~cm}^{-1}$.

\section{Surface oil and total oil analyses}

The methods used for the analysis of surface oil and total oil modification from the previous methods [32]. Surface oil analysis method was a powder with weight $3 \pm 0.1 \mathrm{~g}$ be entered in a conical flask containing $30 \mathrm{ml}$ of hexane was then stirred for $10 \mathrm{~min}$. The suspension was then filtered and the residue rinsed thrice by passing $20 \mathrm{ml}$ of hexane through each time. Powder residue was then dried for $30 \mathrm{~min}$ and weighed. The amount of surface oil was calculated by the difference in weight of the microsphere, before and after washing.

The total oil was determined using soxhlet extraction unit. Accurately weighed microspheres $(3 \mathrm{~g})$ were extracted using $100 \mathrm{ml}$ hexane for $4 \mathrm{~h}$ to ensure complete oil extraction. After extraction, the oil exhausted powder was air-dried to constant weight.

\section{Encapsulation efficiency}

Encapsulation efficiency was calculated using equation from previous methods [30]:

$$
\mathrm{EE}=\frac{\text { Total oil-Surface oil }}{\text { Total oil }} \times 100 \% \ldots \ldots 1 \text { ) }
$$

Surface oil $=$ Original weight-Final weight of microspheres ....2)

Total oil $=$ Original weight-Weight of soxhlet extracted micro-spheres 3 )

\section{RESULTS AND DISCUSSION}

\section{Droplet size of emulsion}

The initial preparation of the encapsulation process was the formation of an emulsion from the mixture solution of chitosan and red ginger oleoresin. In this research also used tween 80 that serves to stabilize the emulsion. Tween 80 is a non-ionic surfactant to emulsify faster with small droplet size [34]. Fig. 1 shows that the emulsion droplet size tends to increase with increasing the ratio between chitosan and red ginger oleoresin. Increases in the ratio indicate increased concentrations of the chitosan solution. The decrease of the wall material concentration can decrease the viscosity, this causes the emulsion droplet size becomes smaller [35]. The increase in viscosity would produce emulsions with larger droplet size and would be produced large microspheres [36].

Besides the influence of the wall material viscosity against of the emulsion droplet size, another factor is the effect of stirring speed. Increase stirring speed will decrease emulsion droplet size and create a more stable emulsion. If the agitation time is too long, emulsifier effectiveness will be decreased because the intense stirring will cause the emulsifier to drop out from the oil-water interface [37]. The size of emulsion droplets in various ratios of oleoresin and chitosan can be summarized in table 1 .

\section{Surface oil}

The success of the encapsulation process is determined by the surface oil from the microcapsules. Surface oil is the amount of oil on the surface of the microcapsules are not coated, this would be detrimental because it will be damaged due to environmental influences. The relatively low encapsulation efficiency (EE) values obtained indicate that high surface oil values would be detrimental to the oxidative stability of the microcapsules [38]. Surface oil was the amount of oil on the surface of the microcapsules that was not coated. The oil on the surface will be damaged due to environmental influences. Encapsulation efficiency will be low, if the amount of surface oil to be great. The high surface oil would be detrimental to the oxidative stability of the microcapsules [38]. 
Based on research that has been conducted, the largest surface oil was obtained from the ratio of chitosan: red ginger oleoresin is $1: 1$ with the inlet temperature of the spray dryer at $180^{\circ} \mathrm{C}$ and in the ratio $2: 1$ with the inlet temperature at $190^{\circ} \mathrm{C}$ were $0.05 \pm 0.004$ grams and $0.05 \pm 0.006$ grams.

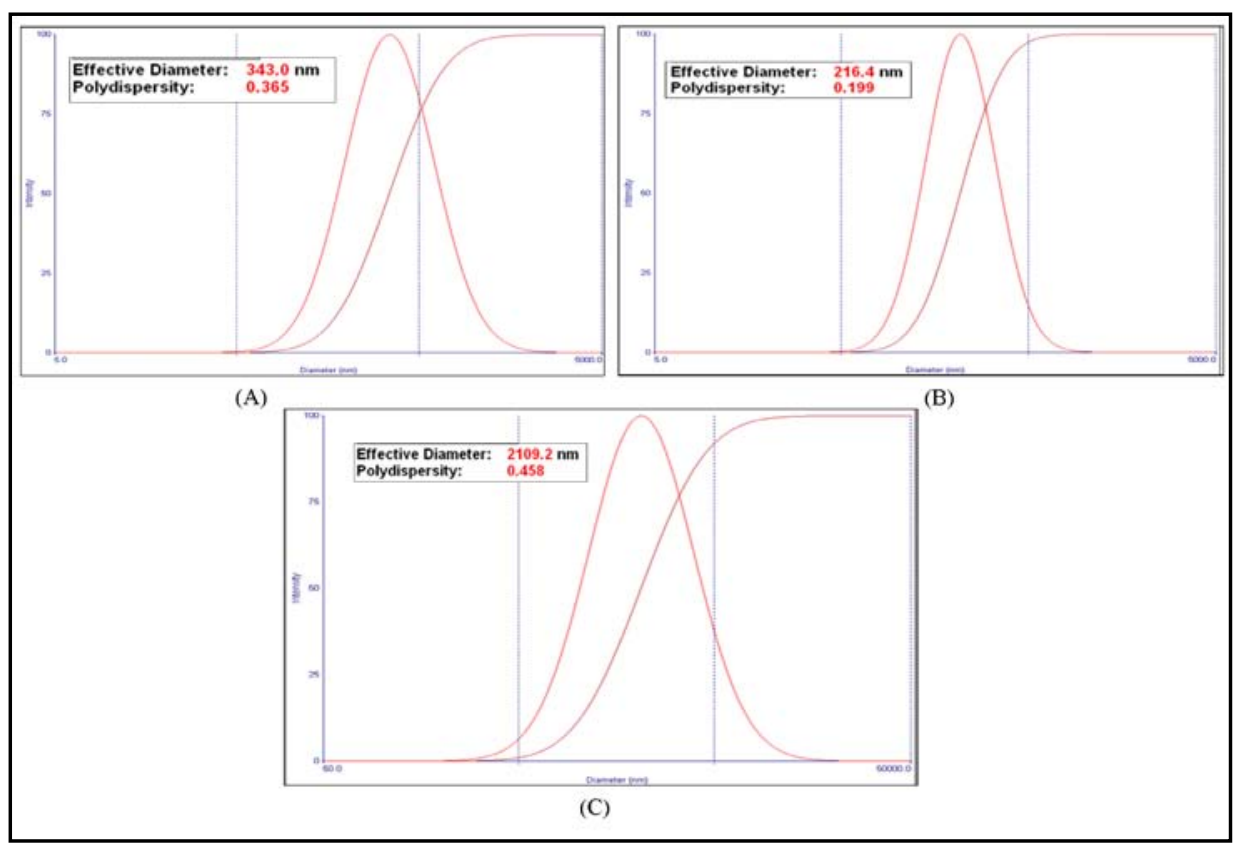

Fig. 1: The emulsion droplet size with different ratio of chitosan: red ginger oleoresin, (A) 1: 1; (B) 2: 1; (C) 3: 1

Table 1: Droplet size of emulsion

\begin{tabular}{ll}
\hline Ratio (Chitosan: Oleoresin) & Droplet size (nm) $^{\mathbf{a}}$ \\
\hline $1: 1$ & $343 \pm 1.5$ \\
$2: 1$ & $216.4 \pm 0.9$ \\
$3: 1$ & $2109.2 \pm 46.1$ \\
\hline
\end{tabular}

amean $\pm S E M, n=5$

The lowest surface oil obtained at a ratio of chitosan with red ginger oleoresin was 3: 1 at the inlet temperature spray drying of $200^{\circ} \mathrm{C}$ that was equal to $0.010 \pm 0.005$ grams. The same result has been reported [31], shows that the declining value of the oil surface due to an increase the ratio of sodium caseinate (wall material): red ginger oleoresin. Increase in the ratio of chitosan with red ginger oleoresin would increase the volume and viscosity of chitosan for coating oleoresin. Increase in the amount of chitosan would increase the wall thickness of microcapsule and reduce the migration of oleoresin to the particle surface. Conversely, a decrease in a number of chitosan microcapsules would make the walls become thinner, so would make oleoresins migrated out during the drying process. Another reason was decreased in the amount of chitosan can cause increased amount of oleoresin was not coated, so it would be stick on the surface of the particles.

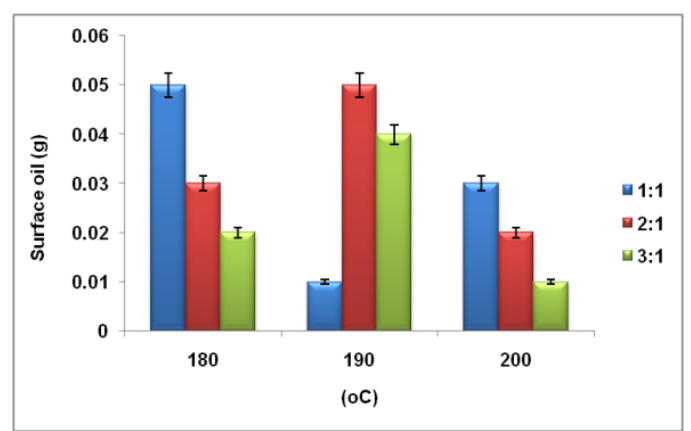

Fig. 2: The effect of spray dryer temperature on the surface oil of microcapsules, *Error Bars represent standard deviation
The value of surface oil was also influenced by the inlet temperature of the spray dryer. Fig. 2 shows that increasing the inlet temperature of spray dryer causes decreased the value of the surface oil at any ratio chitosan with red ginger oleoresin. The temperature in the spray dryer will affect the rate of evaporation of the solvent in emulsion droplets [30], [33]. Increasing the inlet temperature of the spray dryer it would increase the rate of evaporation. This makes the wall material would be faster to harden. It would be reduce the migration rate of oleoresin to the microcapsules surface.

\section{Total oil}

The effect of chitosan: red ginger oleoresin ratio and the inlet temperature of the spray dryer to the total oil can be seen in fig. 3 . The highest value of total oil obtained from the ratio of chitosan: red ginger oleoresin was 3: 1 with the inlet temperature of spray dryer at $200{ }^{\circ} \mathrm{C}$ in the amount of $1.18 \pm 0.02 \mathrm{~g}$.

The lowest value of total oil obtained from $0.3 \mathrm{~g}$ derived from the ratio of chitosan: oleoresin of $1: 1$ with a temperature at $180^{\circ} \mathrm{C}$.

Fig. 3 shows that in general, increasing the ratio of chitosan: oleoresin could increase total oil. Ratio of chitosan: red ginger oleoresin decline may reduce the ability of chitosan to coat oleoresin, so a lot of oleoresin was not coated and would evaporate during the drying process. Another factor that is caused by a decrease in the ratio of chitosan: oleoresin was produced microcapsule walls become thin and may cause the walls of the microcapsules become cracked when the drying temperature increases. 


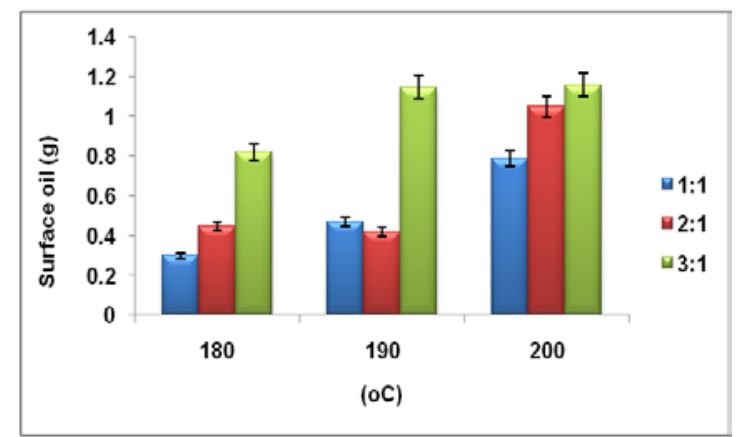

Fig. 4: Total oil microcapsules at various inlet temperature of the spray dryer, *Error Bars represent standard deviation

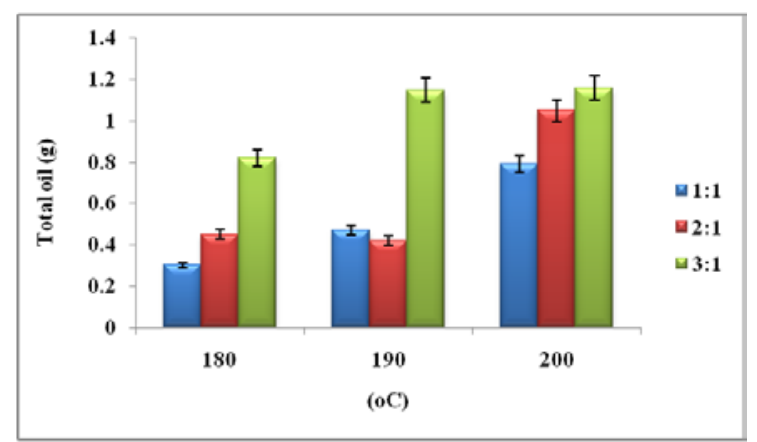

Fig. 4: Total oil microcapsules at various inlet temperature of the spray dryer, *Error Bars represent standard deviation

Effect of the chitosan: red ginger oleoresin ratio and the inlet temperature spray drying to the total oil can be seen in fig. 3 . The highest value of total oil obtained from the ratio of chitosan: red ginger oleoresin at $3: 1$ with $200{ }^{\circ} \mathrm{C}$ of the inlet temperature spray drying in the amount of $1.18 \pm 0.02 \mathrm{~g}$. While the lowest value of total oil obtained of $0.3 \pm 0.06 \mathrm{~g}$ derived from the ratio of chitosan: oleoresin at $1: 1$ and the temperature of $180^{\circ} \mathrm{C}$.

Fig. 3 shows that in general, increasing the ratio of chitosan: oleoresin could increase the total oil. Ratio of chitosan: red ginger oleoresin decline may reduce the ability of chitosan to coat oleoresin, so that a lot of oleoresin was not coated and would be evaporate during the drying process. Another influence, due to the decrease in the ratio of chitosan: Oleoresin is a microcapsule wall becomes thin and could cause the walls of the microcapsules become cracked during the drying process.

When the walls of the microcapsules already cracked, then the value of total oil become low. Reduction in the amount of coating material makes total oil becomes low [39], said that when the amount of coating material was reduced, then the total oil value will be lower. Consequently the amount of oleoresin that coated would be reduced and oleoresin which was not coated will evaporate during the spray drying process.

The rapid drying rate would also possible to make the crust more firms and no further leaching of volatile would happen to the surface [40]. The high inlet temperatures lead to the formation of the semipermeable membrane on the surface of the droplet getting faster. This caused the breakage of the product during the spray drying process [41]. Fig. 3 shows that at $200{ }^{\circ} \mathrm{C}$, total oil produced was higher than the temperature of $180^{\circ} \mathrm{C}$ and $190^{\circ} \mathrm{C}$. This means that chitosan was able to withstand at $200{ }^{\circ} \mathrm{C}$ without cracking.

\section{Encapsulation efficiency}

The high encapsulation efficiency of the microcapsule can be affected by different parameters, such as low solubility of the polymer in organic solvent, high solubility of organic solvent in water, a high concentration of polymer, the rate of solvent removal and rate solidification of microcapsule. The values of encapsulation efficiency in table 2 were calculated based on the total oil and surface oil using equation 1 . The encapsulation efficiency values obtained from this research were ranging from $83.33 \pm 0.42 \%$ $99.15 \pm 0.02 \%$.

Table 2: Encapsulation efficiency

\begin{tabular}{|c|c|c|c|c|}
\hline Ratio (chitosan: oleoresin) & Temperature $\left({ }^{\circ} \mathrm{C}\right)$ & Surface oil (g) ${ }^{a}$ & Total oil (g) $^{\mathbf{a}}$ & Encapsulation efficiency (\%) ${ }^{a}$ \\
\hline \multirow[t]{3}{*}{$1: 1$} & 180 & $0.05 \pm 0.004$ & $0.3 \pm 0.06$ & $83.33 \pm 0.42$ \\
\hline & 190 & $0.01 \pm 0.012$ & $0.47 \pm 0.003$ & $97.87 \pm 0.21$ \\
\hline & 200 & $0.03 \pm 0.004$ & $0.79 \pm 0.05$ & $96.20 \pm 0.85$ \\
\hline \multirow[t]{3}{*}{$2: 1$} & 180 & $0.03 \pm 0.002$ & $0.45 \pm 0.04$ & $93.33 \pm 0.32$ \\
\hline & 190 & $0.05 \pm 0,006$ & $0.42 \pm 0.01$ & $88.10 \pm 0.31$ \\
\hline & 200 & $0.02 \pm 0.003$ & $1.05 \pm 0.2$ & $98.10 \pm 0.54$ \\
\hline \multirow[t]{3}{*}{$3: 1$} & 180 & $0.02 \pm 0.005$ & $0.82 \pm 0.02$ & $97.56 \pm 0.46$ \\
\hline & 190 & $0.04 \pm 0.003$ & $1.15 \pm 0.05$ & $96.52 \pm 0.35$ \\
\hline & 200 & $0.01 \pm 0.005$ & $1.18 \pm 0.02$ & $99.15 \pm 0.02$ \\
\hline
\end{tabular}

aMean \pm SD, $n=3$

The lowest of encapsulation efficiency values obtained from the ratio of chitosan: red ginger oleoresin at 1: 1 with temperature of $180{ }^{\circ} \mathrm{C}$, while the highest value obtained from the ratio of chitosan: oleoresin at 3: 1 and temperature of $200{ }^{\circ} \mathrm{C}$. Increase the ratio of chitosan: red ginger oleoresin would increase the viscosity. When the emulsion droplets contact with the hot air, the diffusion rate of red ginger oleoresin would decrease to the droplet surface, it was indicated by an increase in total oil. Increasing the viscosity of the polymer solution, the diffusion of the drug will be delayed through the polymer membrane [42]. After the polymer solution is compacted, packaged drugs are not easily escaped from the polymer and thus the encapsulation efficiency remains quite high.

The same result has been reported previously [43]. The result of encapsulation efficiency of linoleic acid decreased when the weight of core was increased. The amount of gum arabic as wall materials was not enough for coating all of oil, so the value of encapsulation efficiency was decrease.

\section{Scanning electron microscope (SEM) analysis}

Scanning electron microscopy (SEM) analysis was used to analyze the morphology of the microcapsules. This characteristic analysis was conducted to determine the inlet temperature of a spray dryer and the ratio of chitosan: red ginger oleoresin to the condition of the microcapsules.

Fig. 4 shows that the morphology of the microcapsules was affected by changes of the inlet temperature of a spray dryer and the ratio of chitosan: red ginger oleoresin. At the inlet temperatures were $180^{\circ} \mathrm{C}$ and $190{ }^{\circ} \mathrm{C}$ have produced microcapsules rough surface and wrinkled. This happens because, at low temperatures, the drying rate would decrease so that the solidification process of microcapsules would take longer [44, 45]. Wrinkles microcapsules could be caused by the diffusion of oleoresin from the microcapsules because of slow drying rate. Another cause was the low temperature makes the microcapsule wall would not withstand for a vacuum 
pressure conditions during the analysis process SEM. Surface morphology of microcapsules that was produced from inlet temperature at $200{ }^{\circ} \mathrm{C}$ had a smooth surface, spherical shape and there were no wrinkles.

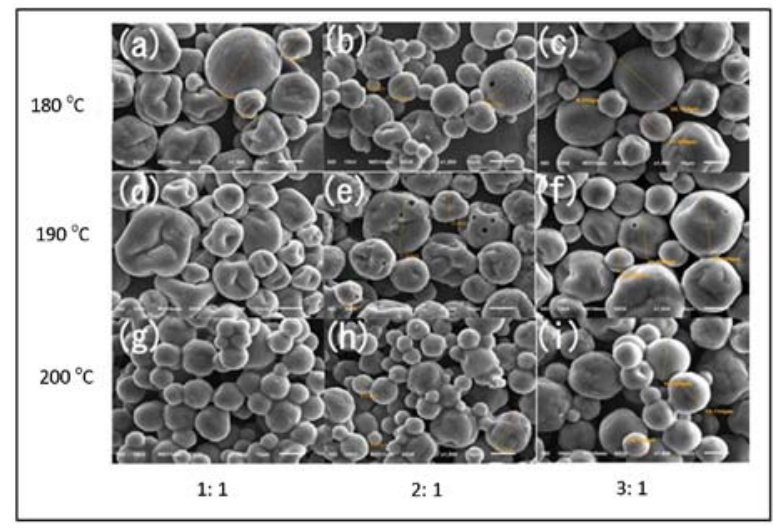

Fig. 5: Morphology of microcapsules

\section{Fourier transform infrared spectroscopy (FTIR) analysis}

Analysis of the interaction of the components in the microcapsules could see in fig. 6 was the result of Fourier transform infrared spectroscopy (FTIR) analysis.

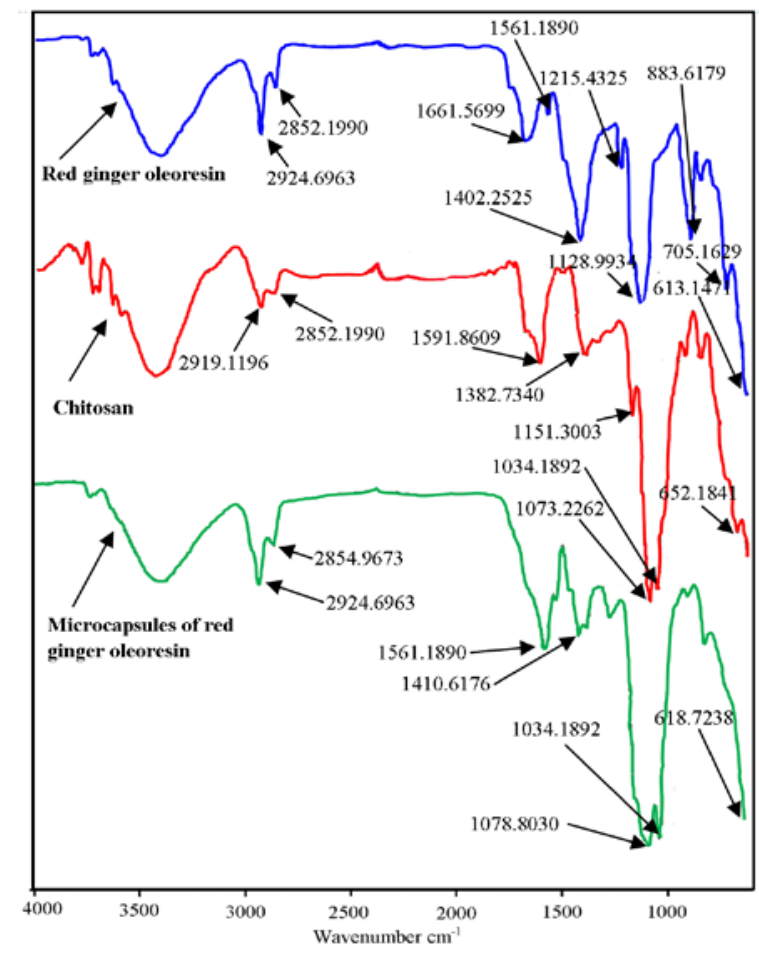

Fig. 6: Fourier transform infrared spectroscopy (FTIR) analysis

The spectrum of chitosan in fig. 6 shows, the 0-H group on the wavenumber of $3433.8 \mathrm{~cm}^{-1}$. C-H emerged in wavenumber of $2919.1196 \mathrm{~cm}^{-1}$. N-H groups in wavenumber of $1591.189 \mathrm{~cm}^{-1}$ which was the bending vibration absorption peaks of the amine group and the low intensity of the $\mathrm{CH}$ group of $\mathrm{CH}_{3}$ groups in the area the wavenumber from 652.1841 to $1034.1892 \mathrm{~cm}^{-1}$. The spectrum of red ginger oleoresin showed an $\mathrm{OH}-\mathrm{H}$ group at wavenumber $2924.7 \mathrm{~cm}-$ 1. The bond of $\mathrm{C}=\mathrm{C}$ at a wavenumber of $1661.57 \mathrm{~cm}^{-1}$. The bond $\mathrm{C}=\mathrm{C}$ aromatic in the band $1561.19 \mathrm{~cm}^{-1}$. The bond of $\mathrm{C}-\mathrm{O}-\mathrm{C}$ at wavenumber $1215.43 \mathrm{~cm}^{-1}$, and the $\mathrm{O}-\mathrm{H}$ group at wavenumber 613.14 to $883.61 \mathrm{~cm}^{-1}$.

FTIR analysis shows that the microcapsules did not appear new peaks for their new functional groups, only a change in the peak width and slightly shifting the frequency. These results indicated the absence of any significant interaction between the microcapsules of red ginger oleoresin with chitosan and red ginger oleoresin.

\section{CONCLUSION}

Based on research that has been done, increasing the inlet temperature of the spray dryer then the encapsulation efficiency was increased, the highest encapsulation efficiency values obtained in spray dryer inlet temperature of $200{ }^{\circ} \mathrm{C}$ with a ratio at $3: 1$. The results of the microcapsules characterization using SEM showed that the surface morphology of the microcapsules was smooth and without wrinkles obtained at $200{ }^{\circ} \mathrm{C}$ and the results of FTIR analysis showed that there were no new functional groups.

\section{ACKNOWLEDGEMENT}

Acknowledgements to the Ministry of research, technology and higher education on funds provided through the research grant in 2016.

\section{CONFLICT OF INTERESTS}

Declare no conflict of interest was reported by the authors.

\section{REFERENCES}

1. Ding SH, An KJ, Zhao CP, Li Y, Guo YH, Wang ZF. Effect of drying methods on volatiles of Chinese ginger (Zingiber officinale roscoe). Food Bioprod Process 2012;90:515-24.

2. Oboh G, Ayodele JA, Adedayo OA. Antioxidant and inhibitory effect of red ginger (Zingiber officinale var. rubra) and white ginger (Zingiber officinale roscoe) on $\mathrm{Fe}^{2+}$ induced lipid peroxidation in rat brain in vitro. Exp Toxicol Pathol 2012;64:31-6.

3. Zick SM, Djuric Z, Ruffin MT, Litzinger AJ, Normolle DP, Alrawi $\mathrm{S}$, et al. Pharmacokinetics of 6-gingerol, 8-gingerol, 10-gingerol, and 6-shogaol and conjugate metabolites in healthy human subjects. Cancer Epidemiol Biomarkers Prev 2008;17:1930-6.

4. Rahmani AH, Al Shabrmi FM, Aly SM. Active ingredients of ginger as potential candidates in the prevention and treatment of diseases via modulation of biological activities. Int J Physiol Pathophysiol Pharmacol 2014;6:125-36.

5. Hasan HA, Rasheed Raauf AM, Abd Razik BM, Rasool Hassan BA. Composition and antimicrobial activity of the crude extracts isolated from Zingiber officinale by different solvents. Pharm Anat Acta 2012;3:1-5.

6. Reineccius G. Source book of flavor. 2nd ed. Netherlands: Springer Science+Business Media B.V; 1994. p. 252.

7. Zachariah TJ. Ginger. In: Parthasarathy VA, Chempakam B, Zachariah TJ. Chemistry of spices. 1st ed. London: CAB International; 2008. p. 70-96.

8. El-Ghorab AH, Nauman M, Anjum FM, Hussain S, Nadeem MA. Comparative study on chemical composition and antioxidant activity of ginger (Zingiber officinale) and Cumin (Cuminum cyminum). J Agric Food Chem 2010;58:8231-7.

9. Vernin G, Parkanyi C. Chemistry of ginger. In: Ravindran PN, Nirmal Babu K. Ginger. The genus Zingiber, Boca Raton. Florida: CRC Press; 2004. p. 87-180.

10. Singh G, Kapoor IPS, Singh P, Heluani CS, Lampasona MP, Cesar ANC. Chemistry antioxidant and antimicrobial investigations on essential oil and oleoresins of Zingiber officinale. Food Chem Toxicol 2008;46:3295-302.

11. Saha A, Blando J, Silver E, Beltran L, Sessler J, Di Giovanni J. 6Shogaol from dried ginger inhibits growth of prostate cancer cells both in vitro and in vivo through inhibition of STAT3 and NF-kB signaling. Cancer Prev Res 2013;7:627-38.

12. Tan BS, Kang O, Mai CW, Tiong KH, Alan ASB, Pichika MR, et al. 6-Shogaol inhibits breast and colon cancer cell proliferation through activation of peroxisomal proliferator activated receptor $\gamma$ (PPAR $\gamma$ ). Cancer Lett 2013;336:127-39. 
13. Lin CB, Lin CC, Tsay GJ. 6-Gingerol inhibits growth of colon cancer cell LoVo via induction of G2/M arrest. J Evidence-Based Complementary Altern Med 2012;1-7. http://dx.doi.org/ $10.1155 / 2012 / 326096$

14. Govindarajan VS. Ginger-chemistry, technology, and quality evaluation: part I. Crit Rev Food Sci Nutr 1982;17:1-96.

15. Shaikh J, Bhosale R, Singhal R. Microencapsulation of black pepper oleoresin. Food Chem 2006;94:105-10.

16. Purseglove JW. Spices. Vol. II, New York: Longman Inc; 1981.

17. Vaidya S, Bhosale R, Singhal RS. Microencapsulation of cinnamon oleoresin by spray drying using different wall materials. Drying Technol 2006;24:983-92.

18. Dubey R, Shami TC, Rao KUB. Microencapsulation technology and applications. Def Sci J 2009;59:82-95.

19. Bansode SS, Banarjee SK, Gaikwad SL, Jadhav R, Thorat RM. Microencapsulation: a review. Int J Pharm Sci Rev Res 2010;1:38-43.

20. Gouin S. Microencapsulation: industrial appraisal of existing technologies and trends. Trend Food Sci Tech 2004;15:330-47.

21. Calvo P, Hernandez T, Lozano M, Gonzalez-Gomez D. Microencapsulation of extra-virgin oil by spray drying: Influence of wall material and olive quality. Eur J Lipid Sci Tech 2010;112:852-8.

22. Kumar A, Sharma PK, Banik A. Microencapsulation as a novel drug delivery system. Int Pharm Sci 2011;1:1-7.

23. Agnihotri N, Mishra R, Goda C, Arora M. Microencapsulation-a novel approach in drug delivery: a review. Indo Global J Pharm Sci 2012;2:1-20.

24. Hejazi R, Amiji M. Chitosan-based gastrointestinal delivery systems. J Controlled Release 2003;89:151-65.

25. Pavanveena C, Kavitha K, Anil Kumar SN. Formulation and evaluation of trimetazidine hydrochloride loaded chitosan microsphere. Int J Appl Pharm 2010;2:11-4.

26. Dziezak JD. Microencapsulation and encapsulated ingredients. Food Tech 1988;42:136-48

27. Gharsallaoui A, Roudaut G, Chambin O, Voilley A, Saurel R. Applications of spray-drying in microencapsulation of food ingredients: an overview. Food Res Int 2007;40:1107-21.

28. Shahidi F, Han XQ. Encapsulation of food ingredients. Crit Rev Food Sci Nutr 1993;33:501-47.

29. Tonon RV, Grosso CRF, Hubinger MD. Influence of emulsion composition and inlet air temperature on the microencapsulation of flaxseed oil by spray drying. Food Res Int 2011;44:282-9.

30. Şahin-Nadeem H, Dinçer C, Torun M, Topuz A, Özdemir F. Influence of inlet air temperature and carrier material on the production of instant soluble sage (Salvia fruticosa Miller) by spray drying. LWT Food Sci Technol 2013;52:31-8.

31. Harimurti N, Nhestricia N, Subardjo SY, Yuliani S. Effect of oleoresin concentration and composition of encapsulating materials on properties of the microencapsulated ginger oleoresin using spray drying method. Indonesian J Agric 2011;4:33-9.
32. Tan LH, Chan LW, Heng PW. Effect of oil loading on microspheres produced by spray-drying. J Microencapsul 2005;22:253-9.

33. Aghbashlo M, Mobli H, Madadlou A, Rafiee S. Influence of wall material and inlet drying air temperature on the microencapsulation of fish oil by spray drying. Food Bioprocess Technol 2013;6:1561-9.

34. Eid AM, Saringat HB, Arafat OM. The effect of surfactant blends on the production of self-emulsifying system. Int J Pharma Frontier Res 2012;2:21-31.

35. Ruo L. Chitosan particles for the controlled release of proteins. Doctoral dissertation. Department of Mechanics. Politecnico di Torino. Italy; 2012.

36. Bhardwaj SB, Shukla AJ, Collins CC. Effect of varying drug loading on particle size distribution and drug release kinetics of verapamil hydrochloride microspheres prepared with cellulose esters. J Microencapsul 1995;12:71-81.

37. Joshi HC, Pandey IP, Kumar A, Garg N. A study of various factors determining the stability of molecules. Adv Pure Appl Chem 2012;1:7-11.

38. Pourashouri P, Shabanpour B, Razavi SH, Jafari SM, Shabani A, Aubourg SP. Impact of wall materials on physicochemical properties of microencapsulated fish oil by spray drying. Food Bioprocess Tech 2014;7:2354-65.

39. McNamee BF, O'Riordan ED, O'Sullivan M. Emulsification and microencapsulation properties of gum arabic. J Agric Food Chem 1998;46:4551-5.

40. Bhandari BR, Dumoulin ED, Richard HMJ, Noleau I, Lebert AM. Flavor encapsulation by spray drying-application to citral and linalyl acetate. J Food Sci 1992;57:217-21.

41. Jafari SM, Assadpoor E, He Y, Bhandari B. Encapsulation efficiency of food flavors and oils during spray drying. Drying Technol 2008;26:816-35.

42. Ganesh S, Kumar DS, Kumar BS, Abhilash R, Bharadwaj PS, Prudhviraj KVS, et al. Controlled release formulation and evaluation of idarubicin microsphere using biodegradable hydrophilic and hydrophobic polymer mixtures. Asian J Pharm Clin Res 2010;3:179-82.

43. Minemoto Y, Hakamata K, Adachi S, Matsuno R. Oxidation of linoleic acid encapsulated with gum arabic or maltodextrin by spray-drying. J Microencapsul 2002;19:181-9.

44. Maa YF, Constantino HR, Nguyen PA, Hsu CC. The effect of operating and formulation variables on the morphology of spray-dried protein particles. Pharm Dev Technol 1997; 2:213-23.

45. Mezhericher M, Levy A, Borde I. Spray drying modelling based on advanced droplet drying kinetics. Chem Eng Proc: Process Intensif 2010;49:1205-13.

\section{How to cite this article}

- Jayanudin, Rochmadi. Encapsulation of red ginger oleoresin (Zingiber officinale var rubrum) with chitosan as wall material. Int J Pharm Pharm Sci 2017;9(8):29-34. 